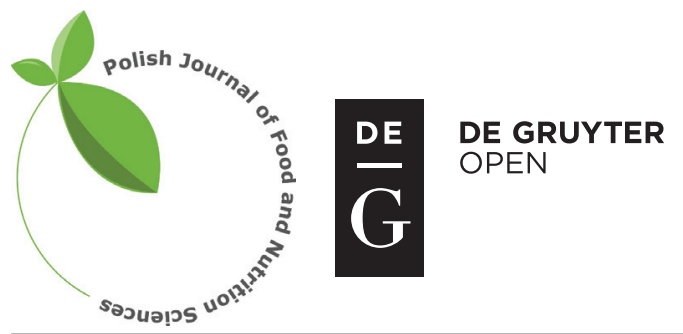

Pol. J. Food Nutr. Sci., 2018, Vol. 68, No. 1, pp. 63-71

DOI: $10.1515 /$ pjfns-2017-0009 http://journal.pan.olsztyn.pl

Original research article

Section: Food Quality and Functionality

\title{
Phytonutrients in Oat (Avena sativa L.) Drink: Effect of Plant Extract on Antiradical Capacity, Nutritional Value and Sensory Characteristics
}

\author{
Anna Gramza-Michatowska ${ }^{1 *}$, Dominik Kmiecik ${ }^{1}$, Joanna Kobus-Cisowska ${ }^{1}$, \\ Anna Żywica ${ }^{1}$, Krzysztof Dziedzic ${ }^{2}$, Anna Brzozowska ${ }^{1}$
}

\author{
${ }^{1}$ Faculty of Food Science and Nutrition, Poznań University of Life Sciences, Wojska Polskiego 31, 60-624 Poznań, Poland \\ ${ }^{2}$ Department of Pediatric Gastroenterology and Metabolic Diseases, Poznan University of Medical Sciences, Poland
}

Key words: oatmeal, stevia, mulberry, yellow tea, antioxidant potential

The purpose of this study was to design the formula and antioxidant potential of gluten-free oat drinks fortified with bioactive plant components. The paper describes the use of three preparations of plant origin: yellow tea leaf extract, mulberry extract and steviol glycosides from stevia leaves. Analyses of the oat drinks basic composition - including proteins, lipids, carbohydrates, dietary fiber fractions and antioxidant properties with DPPH, ABTS, ORAC and FRAP assays were conducted. Tea extract with steviosides oat drink showed the highest total phenolic concentration and the highest antioxidant activity followed by stevia and mulberry oat drink, whereas stevia oat drink showed the lowest phenolics level and weakest antioxidant activity. Moreover, the applied plant components showed moderate ability to influence the sensory values of the fortified oat drinks. The results demonstrate that tea, stevia and mulberry preparations applied in oat drinks enhanced antioxidant potential and might be a natural source of antioxidant components.

\section{INTRODUCTION}

The role of nutrition in the modern world is constantly changing. Food was once seen as a product to keep people alive, and satisfy their hunger, and as a prerequisite for their proper physical and mental development. Results suggest that a properly designed food may serve in the prevention and even treatment of diabetes and celiac disease. In addition, this food would be proposed for the whole population or individuals of the appropriate age, or with an increased risk of the disease [Pang et al., 2012].

Oats (Avena sativa) are a well-recognized source of balanced protein, soluble fiber, minerals and vitamins, as well as polyphenolics and avenanthramides [Butt et al., 2008]. Industrial oat manufacture concentrates mostly on processing oats into flakes, groats, bran and flour, which are further used in food production or cooking. The main oat fiber fraction, $\beta$-glucans, reduces glucose levels in the blood of people with type II diabetes and in obese people, additionally, the main oat fraction is a probiotic [Behall et al., 2005]. Studies on the effect of oat drinks on the human body show a positive effect on the level of total cholesterol and the LDL fraction, resulting in a reduced risk of coronary heart disease, hypertension, and colorectal cancer [Önning et al., 1999], and are recommended in a gluten-free diet [Hüttner \& Arendt, 2010].

\footnotetext{
* Corresponding Author: Tel. +4861 84873 31; Fax +4861 8487430

E-mail: angramza@up.poznan.pl (PhD A. Gramza-Michałowska)
}

The addition of plant preparations is a frequent practice in the food industry. The most popular plant used in diabetes treatment is mulberry (Morus alba), consumed as dried fruit or in the form of leaf infusions, as well as dietetic supplements. Not without significance is the content of polyphenolic compounds, such as: quercetin-3-O-(6-malonylglucoside) kaempferol-3-O-(6-malonylglucoside), isoquercitrin, rutin, astragalin, tannins, coumarins (skopolin and skimin), and phenolic acids (chlorogenic and caffeic) [Ercisli \& Orhan, 2007]. The biologically-active ingredients of mulberry leaves are antidiabetic alkaloids, mainly 1-deoxynojirimycin (DNJ) and its derivatives, inhibiting enzymes responsible for sugar degradation and preparation for absorption [Vichasilp et al., 2012]. Research has shown that the consumption of a mulberry leaf infusion suppresses postprandial glucose and reduces insulin secretion, prevents oxidative stress, furthermore, its components could inhibit the formation of cancer, act as an anti-allergic, anti-obesity, and antiatherogenic agents, and decrease Alzheimer's disease risk by inhibiting the neurotoxicity of betaamyloid [Kimura et al., 2007; Niidome et al., 2007].

Another well proven antioxidant source are tea leaves (Camellia sinensis), characterized by a low nutritional value and containing strong antioxidants, mainly catechins and alkaloids (caffeine), which exert a wide-ranging physiological influence on the human body [Gramza-Michałowska, 2014]. Tea components participate in the prevention of arteriosclerosis, cancer and are strong antioxidants in terms of the presence of both radicals and lipids. Simultaneously, tea brews exert 
a high health-promoting impact, a beneficial effect on gastrointestinal tract function, facilitate digestion, urinary tract and kidney protection, act as a diuretic, influence the nervous, respiratory, circulatory and cardiovascular systems, by lowering blood pressure, and show strong bactericidal and bacteriostatic activity [Sajilata et al., 2008; Budryn et al., 2013; Bajerska et al., 2015; Gramza-Michałowska et al., 2016; Kujawska et al., 2016]. The above cited publications have been conducted on green tea's antioxidant potential and impact on the human body; however, this fact is still under investigation for the other types of teas, especially those subjected to fermentation e.g. yellow tea.

Stevia leaves (Stevia rebaudiana Bertoni) have a distinctive sweet flavor, nearly 40 times sweeter than sucrose, with a low energy contribution. They contain compounds with a similar structure relative to each other, identified as steviol glycosides: rebaudioside (A, B, C, D, E and F), stevioside, steviolbioside, dulcoside $\mathrm{A}$, and rubuzozide. The results of many studies have shown that stevia may have an impact on reducing blood pressure levels and may assist in diabetes treatment, particularly type II, exhibit anti-bacterial, anti-immunomodulatory and anti-oxidative activity [Gregersen et al., 2004; De et al., 2013].

The functional food market is looking for the new products, containing natural additives that are non-toxic in traditional dosage, and implement some health value to the daily diet. Since the consumption of lactose-free products became an increasing trend, the oatmeal drinks with the addition of natural components could be the answer to the growing consumers demand for health-promoting food with biological activity and a high nutritional value. Therefore, we decided to investigate the nutritional value and antioxidative activity of oat drinks enriched with tea and mulberry extracts, sweetened with stevia components in order to confirm potential health benefits and sensory value of products recommended for consumers suffering from lactose intolerance, cardiovascular diseases, diabetes, and those who are health conscious. The antioxidant potential of some oat products and preparations has been demonstrated. However, there is no report about antioxidant activities of oat drinks fortified with plant components with a high biological influence. In this study, the antioxidant potential of enriched oat drinks was examined for the first time. The purpose of this study was to establish formula and antioxidant potential of oat drinks enriched with bioactive plant components recommended both for consumers with diabetes and as a gluten-free drink.

\section{MATERIALS AND METHODS}

\section{Plant material}

The tea (Camellia sinensis) extract was prepared according to the method presented by Gramza-Michałowska et al. [2015]. For the purpose of the research, dried leaves of yellow tea Kekecha were purchased from supplier, originating from certified cultivation in China Guangdong province. Mulberry leaves (Morus alba L. Polish variety: Wielkolistna żółwińska), originating from certified cultivation of Institute of Natural Fibers and Medicinal Plants, Poznan, Poland, were harvested fresh. Prior to the extraction, mulberry leaves were dried at a temperature of $60 \pm 1^{\circ} \mathrm{C}$, and ground to a powder. Extraction procedure included water extraction at $85^{\circ} \mathrm{C}(1: 10 \mathrm{w} / \mathrm{v})$, afterwards the liquid was concentrated $\left(75^{\circ} \mathrm{C}\right.$, for $7.5-10 \mathrm{~h}$ at $0.6-0.8 \mathrm{MPa}$ ) and freeze-dried. The powdered extract was stored in a freezer until analyzed. Aqueous extract yield was as follows: yellow tea $-21.2 \%$, and mulberry leaves -- $6.7 \%$. Steviol glycosides (Stevia rebaudiana) were added in the form of a commercially-available sweetener (E 960, Cargill, USA).

The basic ingredient for designed drink preparation was oatmeal (Avena sativa) with the following nutritional value: energy - $1530 \mathrm{~kJ} / 366 \mathrm{kcal}$, protein - 11.9\%, carbohydrates $69.3 \%$, and lipids $-7.2 \%$ (Stoislaw Mills, Poland). Dried oatmeal $(200 \mathrm{~g})$ was sorted and soaked in $650 \mathrm{~mL}$ of $\mathrm{ddH}_{2} \mathrm{O}$ for $12 \mathrm{~h}$ at ambient temperature. In the next step, the solids were removed and the liquid was separated. The ready-to-consume oat drink was mixed with additives until complete dissolution and then stored. Plant extracts were added in optimized concentrations: mulberry $(0.5 \% \mathrm{w} / \mathrm{v})$, yellow tea $(0.3 \% \mathrm{w} / \mathrm{v})$. Selected samples were also sweetened with steviol glycosides $(0.75 \% \mathrm{w} / \mathrm{v})$. Optimization process was conducted according to sensory evaluations of the final product. The range of the applied concentration was $0.1-5.0 \% \mathrm{mw} / \mathrm{v}$ (data not presented). Ultimately, oat drink composition that received consumers acceptance had been chosen for further research. To evaluate changes in the antioxidant activity during oat drink storage, the samples were stored in a cooler $\left(4-7^{\circ} \mathrm{C}\right)$, and protected from light for 5 days. Oat drinks were filtered with syringe filters (Membrane Solutions PTFE $0.45 \mu \mathrm{m}$ ), and the supernatant was stored in a dark, cool place prior further analysis.

\section{Chemical analysis}

The chemical composition of the oat drinks with additives included protein, lipid, carbohydrate and fiber contents. Protein content was determined with the Kjeldahl method using a conversion factor: 6.25 for cereal [AOAC 1995]. Lipid content of freeze-dried drinks was determined with the Soxhlet method [PN EN ISO 3947:2001P]. Ash content was determined after complete burning of the sample in an oven (Nabertherm Controller P320) [PN A-79011-8:1998]. Total (TDF), insoluble (IDF) and soluble (SDF) dietary fiber content was evaluated enzymatically according to the Asp's method [Dziedzic et al., 2012]. The assumption of the method is based on dietary fiber determination under conditions similar to those found in the human alimentary tract with the use of the following enzymes: $\alpha$-amylase, pepsin and pancreatin, and performed using a Fibertec 1023 System apparatus.

Total phenolics content (TPC) was determined according to the method presented by Shahidi \& Naczk [1995], involving the Folin-Ciocalteu reagent and the reduction of colored complexes at $\lambda=725 \mathrm{~nm}$ (SPECORD ${ }^{\circledR} 40$, Analytik Jena). The results of TPC content assays were evaluated based on the standard curve $\left(y=2.6654 x-0.0441, R^{2}=0.9959\right)$, and expressed as mg of ferulic acid equivalents (FAE)/100 g product.

The DPPH radical scavenging effect of oat drinks was determined according to the procedure described by Sanchez-Moreno et al. [1998]. The decrease of samples absorbance was measured at $\lambda=515 \mathrm{~nm}$ (SP-830 Plus, Metertech). The violet color of the DPPH${ }^{\bullet}$ solution (2,2-diphenyl-1-pic- 
rylhydrazyl) is diminished in the presence of free radical scavengers. The DPPH radical scavenging percentage was evaluated based on the standard curve $(y=336.62 x-0.3583$, $\mathrm{R}^{2}=0.9998$ ), and presented as mg of Trolox equivalent (TE) in $100 \mathrm{~g}$ product.

The $\mathrm{ABTS}^{+}{ }^{*}$ scavenging activity of oat drinks was measured according to the TEAC assay (Trolox Equivalent Antioxidant Capacity) [Re et al., 1999]. The assay is based on the spectrophotometric measurement ( $\lambda=734 \mathrm{~nm}, \mathrm{SPECORD}^{\circledR} 40$, Analytik Jena) of antioxidants ability to scavenge the blue-green colored ABTS radical cation formed from ABTS (2,2'-azinobis-(3-ethylbenzothiazoline-6-sulfonic acid) by oxidation with potassium persulfate. The ABTS radical cation scavenging percentage was evaluated on the basis of the standard curve $\left(y=673.24 x-0.3573, R^{2}=0.9998\right)$, and expressed as mg of Trolox equivalent (TE)/100 g product.

The Ferric Reducing Antioxidant Power assay (FRAP) is based on the ability of components with reducing potential to reduce the TPTZ complex (Fe(III)-2,4,6-tri(2-pirydyl)-striazine) into Fe(II)-TPTZ [Benzie \& Strain, 1996]. The assay is based on the spectrophotometric measurement of the intensity of the produced blue color $\left(\lambda=583 \mathrm{~nm}\right.$, SPECORD ${ }^{\circledR} 40$, Analytik Jena). The FRAP values were evaluated on the basis of the standard curve $\left(y=0.6882-0.0086, R^{2}=0.9996\right)$, and presented as $\mathrm{mg} \mathrm{FeSO}_{4} / 100$ g product.

The Oxygen Radical Absorbance Capacity Assay $\left(\mathrm{ORAC}_{\mathrm{FL}}\right)$ is based on the procedure reported by GramzaMichałowska et al. [2016]. The assay is based on the ability of the antioxidants to scavenge peroxyl radical using a fluorescein solution (FL). Readings were made in a fluorescence spectrophotometer (Hitachi F-2700) at an excitation wavelength of $493 \mathrm{~nm}$ and an emission wavelength of $515 \mathrm{~nm}$. The results were evaluated on the basis of a standard curve for $\mathrm{y}=0.6424 \mathrm{x}-4.5062\left(\mathrm{R}^{2}=0.9828\right)$, and expressed as $\mu \mathrm{mol} / \mathrm{L}$ of Trolox equivalents (TE)/100 g product.

\section{Sensory evaluations}

The analysis of oat drinks with additives was conducted with a 33 member consumer panel, using a hedonic, unstructured scale (1-10) with border variants [ISO 11136:2014]. Sensory evaluations were conducted in a 6-station sensory analysis room; all the consumers were trained prior the testing procedure. The panelists were asked to evaluate the prod- ucts for taste, consistency, aroma, color and overall acceptance in three different sessions. The ratings were made on a 10-point hedonic scale, ranging for each attribute from 10 (like extremely) to 1 (dislike extremely). Mean, variance, and standard deviation measures were calculated for all the attributes of each sample and session separately.

\section{Statistical analysis}

All values represent the means of three independent experiments performed in three repetitions. Data were analyzed using one-way analysis of variance ANOVA $(\mathrm{p}<0.05)$ to determine differences between the mean values determined for the tested samples as well as Tukey's multiple-range test. Pearson correlation coefficients were determined as well. Differences were considered significant at $p<0.05$. Statistica TMPL 10.0 software (StatSoft) was used for the analysis.

\section{RESULTS AND DISCUSSION}

Growing evidence showing the incidence of common civilization diseases has resulted in the undertaking of research aimed at finding food ingredients freely available and cost-efficient with potential health-promoting effects. Food may be responsible for these properties, especially food rich in phenolic compounds and dietary fiber. Many research have shown the high health-promoting impact of phytonutrients from white mulberry, tea catechins, and stevia [Nam et al., 2012].

The proximate chemical composition of oat drinks is presented in Tables 1 and 2. Analysis of protein content showed the highest content in the sample with the addition of steviol glycosides + mulberry extract, and steviol glycosides + tea extract ( 0.683 and $0.670 \mathrm{~g} / 100 \mathrm{~g}$, respectively), while the lowest one in the sample with the addition of mulberry extract $(0.404 \mathrm{~g} / 100 \mathrm{~g})$. The lowest lipid content was also determined in the sample with the addition of mulberry $(0.216 \mathrm{~g} / 100 \mathrm{~g})$, while the highest was found in the sample with the addition of steviol glycosides $(0.391 \mathrm{~g} / 100 \mathrm{~g})$. The differences in lipid content noted between oat drinks with mulberry and oat drink with tea extract were smaller than in the other samples due to a low concentration in the applied aqueous plant extracts. However, the addition of steviol glycosides reduced the differences in comparison to the control sample. The differences could be due to the applied ratio of additives, which in conclu-

TABLE 1. Proximate composition of oat drinks with the addition of plant extracts and steviol glycosides $(\mathrm{g} / 100 \mathrm{~g})$.

\begin{tabular}{l|c|c|c|c}
\hline Sample & Protein & Lipid & Carbohydrates & Ash \\
\hline O & $0.525 \pm 0.009^{\mathrm{b}}$ & $0.332 \pm 0.006^{\mathrm{c}}$ & $4.22 \pm 0.29^{\mathrm{a}}$ & $0.064 \pm 0.013^{\mathrm{a}}$ \\
OSM & $0.683 \pm 0.002^{\mathrm{d}}$ & $0.328 \pm 0.003^{\mathrm{c}}$ & $6.51 \pm 0.57^{\mathrm{c}}$ & $0.169 \pm 0.007^{\mathrm{d}}$ \\
OST & $0.670 \pm 0.019^{\mathrm{c}}$ & $0.329 \pm 0.003^{\mathrm{c}}$ & $5.06 \pm 0.50^{\mathrm{b}}$ & $0.105 \pm 0.010^{\mathrm{c}}$ \\
OM & $0.404 \pm 0.033^{\mathrm{a}}$ & $0.216 \pm 0.003^{\mathrm{a}}$ & $3.92 \pm 0.55^{\mathrm{a}}$ & $0.235 \pm 0.017^{\mathrm{e}}$ \\
OT & $0.541 \pm 0.034^{\mathrm{b}}$ & $0.253 \pm 0.002^{\mathrm{b}}$ & $4.33 \pm 0.62^{\mathrm{a}}$ & $0.096 \pm 0.004^{\mathrm{b}}$ \\
OS & $0.603 \pm 0.009^{\mathrm{c}}$ & $0.391 \pm 0.004^{\mathrm{d}}$ & $6.49 \pm 0.83^{\mathrm{c}}$ & $0.075 \pm 0.007^{\mathrm{b}}$ \\
\hline
\end{tabular}

Sample abbreviations: O - oat; OSM - oat, steviol glycosides, mulberry; OST - oat, steviol glycosides, tea; OM - oat, mulberry; OT - oat, tea; OS - oat, steviol glycosides.

Data expressed as mean \pm standard deviation $(n=3)$. Values in the same column with different letters are significantly different $(p<0.05)$. 
TABLE 2. Total, insoluble and soluble dietary fiber in oat drinks with the addition of plant extracts and steviol glycosides (g/100 g).

\begin{tabular}{l|c|c|c}
\hline Sample & TDF & IDF & SDF \\
\hline O & $1.112 \pm 0.023^{\mathrm{c}}$ & $0.875 \pm 0.041^{\mathrm{c}}$ & $0.236 \pm 0.007^{\mathrm{a}}$ \\
OSM & $1.206 \pm 0.025^{\mathrm{c}}$ & $0.854 \pm 0.035^{\mathrm{c}}$ & $0.352 \pm 0.014^{\mathrm{b}}$ \\
OST & $1.260 \pm 0.033^{\mathrm{c}}$ & $0.638 \pm 0.036^{\mathrm{b}}$ & $0.621 \pm 0.035^{\mathrm{c}}$ \\
OM & $0.741 \pm 0.016^{\mathrm{a}}$ & $0.542 \pm 0.031^{\mathrm{a}}$ & $0.199 \pm 0.004^{\mathrm{a}}$ \\
OT & $0.939 \pm 0.008^{\mathrm{b}}$ & $0.553 \pm 0.004^{\mathrm{a}}$ & $0.386 \pm 0.013^{\mathrm{b}}$ \\
OS & $1.036 \pm 0.009^{\mathrm{bc}}$ & $0.717 \pm 0.008^{\mathrm{b}}$ & $0.318 \pm 0.009^{\mathrm{b}}$ \\
\hline
\end{tabular}

Sample abbreviations: O - oat; OSM - oat, steviol glycosides, mulberry; OST - oat, steviol glycosides, tea; OM - oat, mulberry; OT - oat, tea; OS - oat, steviol glycosides; TDF - total dietary fiber; IDF - insoluble dietary fiber; SDF - soluble dietary fiber.

Data expressed as mean \pm standard deviation $(n=3)$. Values in the same column with different letters are significantly different $(p<0.05)$.

sion influenced nutrient contribution. Carbohydrate content was the highest in the samples with steviol glycosides and steviol glycosides + mulberry extract. The highest ash content was determined in oat drinks with the addition of mulberry extract $(0.235 \mathrm{~g} / 100 \mathrm{~g})$, while the lowest was in the control sample $(0.064 \mathrm{~g} / 100 \mathrm{~g})$, suggesting a higher mineral content in the mulberry than in the tea extract.

Dietary fiber was determined as the total (TDF), soluble (SDF) and insoluble (IDF) fractions. The highest total fiber content was determined in the oat drinks with the addition of steviol glycosides + tea and with steviol glycosides + mulberry (1.260 and $1.206 \mathrm{~g} / 100 \mathrm{~g}$, respectively), while the lowest was found in the drink with added mulberry extract $(0.741 \mathrm{~g} / 100 \mathrm{~g})$. The analysis of the soluble fraction indicated the highest fiber content in the sample with the addition of steviol glycosides + tea extract $(0.621 \mathrm{~g} / 100 \mathrm{~g})$, while the lowest was in the sample with the addition of mulberry extract $(0.199 \mathrm{~g} / 100 \mathrm{~g})$. The highest, similar to the control sample, content of the insoluble fraction of dietary fiber was determined in the sample with the addition of steviol glycosides + mulberry extract $(0.854 \mathrm{~g} / 100 \mathrm{~g})$, while the lowest IDF content was found in the samples with added mulberry $(0.542 \mathrm{~g} / 100 \mathrm{~g})$ and tea extracts $(0.553 \mathrm{~g} / 100 \mathrm{~g})$.

Differences in protein content between oat drinks with steviol glycosides and that with mulberry could be due to different percentages of additives used and further proportions, which influenced the ratio between each of the analyzed components. However, the interactions between polyphenols and protein are also likely to occur. There are different types and mechanisms of polyphenols-protein interactions which lead to polymerization and undesirable decrease in protein solubility [Prigent et al., 2009]. These changes include crosslinking of the proteins, and further change of the protein molecules net charge, affecting their solubility. It also applies to the hydrogen bonding and non-polar hydrophobic interactions resulting in precipitation of proteins with tannins, and making them insoluble and indigestible [Duodu et al., 2003; Ozdal et al., 2013]. It was also observed that the polyphenols-protein interactions influenced the total antioxidant activity [Ozdal et al., 2013].
Results obtained for the total phenolic compound (TPC) content showed a high impact of the plant extracts added (Table 3). The content of TPC in fortified oat drinks ranged from 61.94 to $707.20 \mathrm{mg}$ FAE/100 g. The highest TPC content was determined in the sample with the addition of steviol glycosides + tea extract and in the sample with tea extract (707.2 and $620.15 \mathrm{mg} \mathrm{FAE} / 100 \mathrm{~g}$, respectively), while the lowest was in the control sample and oat drink with steviol glycosides (61.94 and $61.94 \mathrm{mg}$ FAE/100 g, respectively). The storage of oat drinks for $120 \mathrm{~h}$ significantly decreased total phenolics content, i.e. by approximately $8-56 \%$ $(p<0.05)$. The greatest decrease was determined in the sample with the addition of steviol glycosides + mulberry extract $(56.4 \%)$, while the lowest was in the sample with the addition of mulberry extract (8.2\%). It was noted that the addition of mulberry extract and the simultaneous addition of steviol glycosides with tea extract inhibited the decrease in the phenolic compounds content, while the simultaneous addition of steviol glycosides with mulberry extract negatively affected the retention of these compounds in oat drinks. A comparison of the additives effect on the total phenolics content confirmed its significant increase in samples fortified with tea and mulberry extract. Research have shown that tea extracts contain a significant amount of polyphenols, mainly catechins (EGC, C, EC, ECG, GC, GCG and EGCG), they were also shown to contain gallic acid, caffeic acid, rutin and quercetin [Kujawska et al., 2016]. Also, the mulberry extract is characterized by a significant content of polyphenols, ranging from 345.20 to $631.53 \mathrm{mg} \mathrm{GAE} / 100 \mathrm{~g}$, with the predominant ones being: caffeic acid, quercetin-3-O-rhamnoside, quercetin-7-O-glucoside, kaempferol-7-O-glucoside, quercetin-3-O-glucoside and kaempferol-3-O-(6-malonyl)glucoside [Thabti et al., 2012]. Results reported by Le Bourvellec et al. [2012] showed interactions of polyphenols with cell walls of fruit, and led to a conclusion that procyanidins are retained in the tissue, whereas others migrate into the cooking water. The interaction between tannins and cell walls was also discussed, suggesting no relation to protein, but pectin content. The abovementioned interactions could have a significant impact on product's final antioxidant activity. It has been proven, that phytonutrients like proteins, carbohydrates and lipids have a very complex structure which links polyphenols and in result changes their availability for radical scavenging assay evaluations [Jakobek, 2015]. Research of Riou et al. [2002] suggested co-aggregation between polysaccharides and tannins, which influenced the properties of wine.

The antioxidant activity of the oat drinks was determined in this study using the following antiradical activity assays: DPPH, ABTS, and ORAC tests and the ability to reduce ferric ions via FRAP. The results of the above analyses are presented in Table 3. Evaluation of the DPPH radical scavenging ability showed a high activity of the additives used. Plant extracts addition to the samples allowed a 20-30\% increase in the antioxidant activity in comparison to the control sample. In terms of DPPH, the radical scavenging ability of oat drinks may be ordered as follows: steviol glycosides + yellow tea extract $>$ yellow tea extract $>$ mulberry extract $=$ steviol glycosides + mulberry extract $>$ control sample $>$ steviol glycosides. After 120 hours of storage in the cooler, it was found that the simul- 


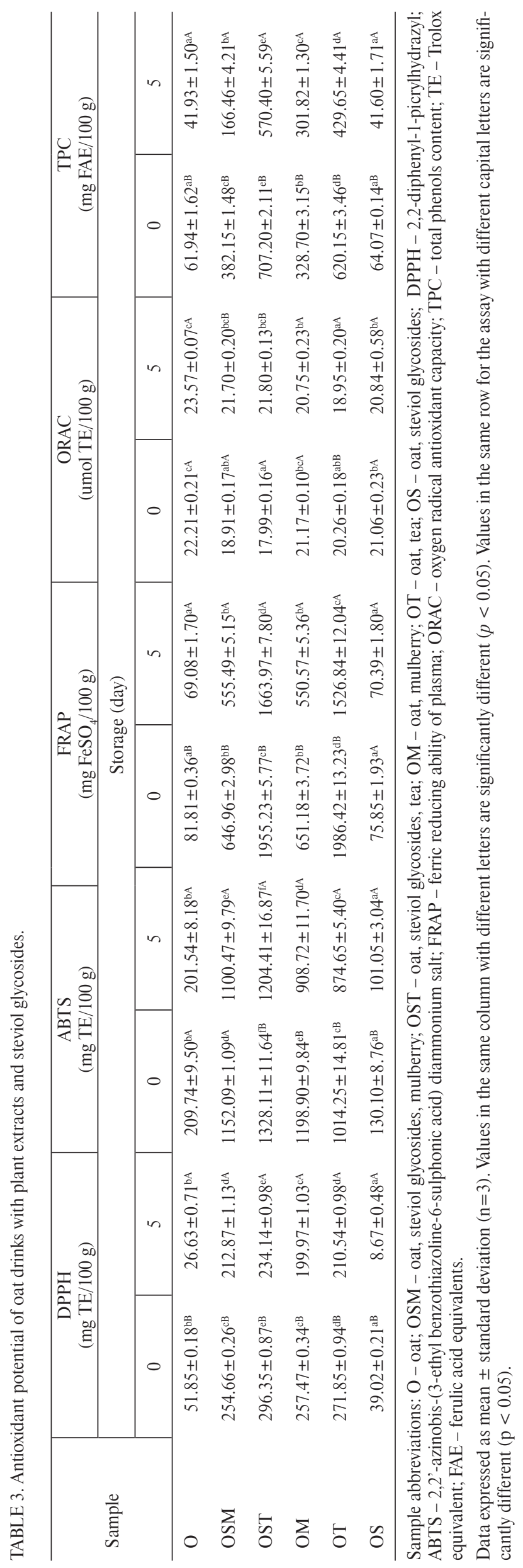

taneous addition of steviol glycosides with mulberry extract and steviol glycosides with tea extract significantly affected the DPPH radical scavenging ability. The addition of steviol glycosides resulted in a significant reduction of the oat drink phytonutrients antiradical capacity in comparison with the unfortified oat drink (77.8\%).

The analysis of oat drinks ability to scavenge the ABTS radical cation showed the high activity of the additives used. It was shown that the addition of plant extracts allowed a 5 -fold increase in the antiradical activity. The highest activity in the TEAC assay was determined for the sample with the addition of steviol glycosides + tea extract $(1328.11 \mathrm{mg}$ $\mathrm{TE} / 100 \mathrm{~g}$ ), followed by mulberry (1198.9 mg TE/100 g), while the lowest was for the sample with steviol glycosides (130.1 mg TE/100 g). The addition of mulberry and steviol glycosides resulted in a significant reduction in the antiradical capacity of the stored beverages (24 and 22\%, respectively). Other studies on the antioxidant activity of oat products indicated that oatmeal possessed the highest ABTS radical cation scavenging capacity $(3.2 \mu \mathrm{mol} \mathrm{TE} / \mathrm{g})$; however, it was inferior to oat cereal in terms of DPPH radical scavenging capacity [Yu et al., 2002]. Total phenols content was twice as high in oatmeal as in oat cereals ( 0.52 and $0.27 \mathrm{mg} \mathrm{GAE} / \mathrm{g}$ ). Sun et al. [2006] investigated the antioxidant activities of oat groat extracts and found that the highest TPC content was as following: methanol 26.17, acetone 12.83, and hexane $8.56(\mu \mathrm{g}$ of $\mathrm{CE} / \mathrm{g}$ ). Concerning the DPPH radical scavenging activities, results were the highest for methanol $(0.79 \mu \mathrm{mol} \mathrm{TE} / \mathrm{g})$, acetone $(0.68 \mu \mathrm{mol} \mathrm{TE} / \mathrm{g})$, and the lowest for hexane oat extract $(0.35 \mu \mathrm{mol} \mathrm{TE} / \mathrm{g})$. Tadhani analyzed the total phenolic compounds and found their contents to be $25.18 \mathrm{mg}$ of GAE/g in stevia leaves and $35.86 \mathrm{mg} \mathrm{GAE} / \mathrm{g}$ in callus on dry weight basis [Tadhani et al., 2007]. The concentrations required to induce a 50\% inhibition of the DPPH radicals of stevia leaves and callus in various extracts ranged from $33.17 \%$ to $56.82 \%$ and were higher for the leaf extract.

The results of FRAP assays showed that the highest reducing potential was determined in the oat drink with addition of tea extract (1986.42 $\mathrm{mg} \mathrm{FeSO}_{4} / 100 \mathrm{~g}$ ), while the lowest was in the sample with steviol glycosides ( $75.85 \mathrm{mg} \mathrm{FeSO}_{4} / 100 \mathrm{~g}$ ). Oat drink enrichment with tea extracts allowed an increase of the reducing potential by up to 24 times, while mulberry extract recorded only a 7-fold increase as compared with the control sample. No similar effect was noted in the samples of oat drink with the addition of steviol glycosides, which activity was similar to the control sample without additives. Five days of storage of oat drinks in a cooler showed that the simultaneous addition of steviol glycosides with mulberry and tea extract contributed to a significant decrease in the $\mathrm{FeSO}_{4}$ reduction potential $(23 \%)$. Other additives, however, resulted in activity reduction by approximately $15 \%$.

The analysis of peroxyl radical scavenging ability in the ORAC assay showed a comparable activity of the additives used. In terms of the ORAC values, the examined oat drinks may be ordered as follows: steviol glycosides + yellow tea extract $\leq$ steviol glycosides + mulberry extract $\leq$ yellow tea extract $\leq$ steviol glycosides $\leq$ mulberry extract $<$ control sample. It was found that the addition of plant extracts and steviol glycosides to the oat drinks negatively affected ORAC activity 
(Table 3). The activity comparable to the control sample was recorded in the samples with the mulberry extract $(21.17 \mu \mathrm{mol}$ $\mathrm{TE} / 100 \mathrm{~g})$, steviol glycosides $(21.06 \mu \mathrm{mol} \mathrm{TE} / 100 \mathrm{~g})$, and tea extract $(20.26 \mu \mathrm{mol} \mathrm{TE} / 100 \mathrm{~g})$. The remaining samples were less active. Five-day storage resulted in the increase of ORAC values in the control sample and in the samples with steviol glycosides + mulberry extract and steviol glycosides + tea extract. The other oat drinks were characterized by a decreased activity against peroxyl radicals in the ORAC assay. The studies of Alarcon et al. [2008] indicate the high antiradical potential of tea extracts in combination with fluorescein (ORAC), where the highest activity was found for an infusion of black tea (2329-2957 mg gallic acid/L), followed by green tea (2086 mg gallic acid/L), and the lowest for white tea (1721 mg gallic acid/L) [Alarcon et al., 2008]. Results reported by other authors also indicate a higher potential for quenching radicals by the extract of green tea compared to red or black teas [Yen \& Chen, 1995]. Unfortunately, there are only few reports in the literature on the activity of yellow tea ingredients. A higher radical scavenging activity was demonstrated by the unfermented tea extracts than the fermented ones, but the highest activity was found in the samples with the addition of partially-fermented yellow tea extracts [Gramza-Michałowska et al., 2015]. Therefore, yellow tea has a considerable amount of catechins, but it also contains some products of oxidation, such as theaflavins and thearubigins, that may affect its high antioxidant activity.

Results of the statistical analysis indicated a strong correlation between results of the antioxidant assays: DPPH, ABTS, TPC and FRAP (Table 4). Antioxidant activity evaluated for oat drinks fortified with plant additives showed the highest compliance for the results of DPPH and ABTS methods as well as DPPH and FRAP. The results obtained in ORAC as-
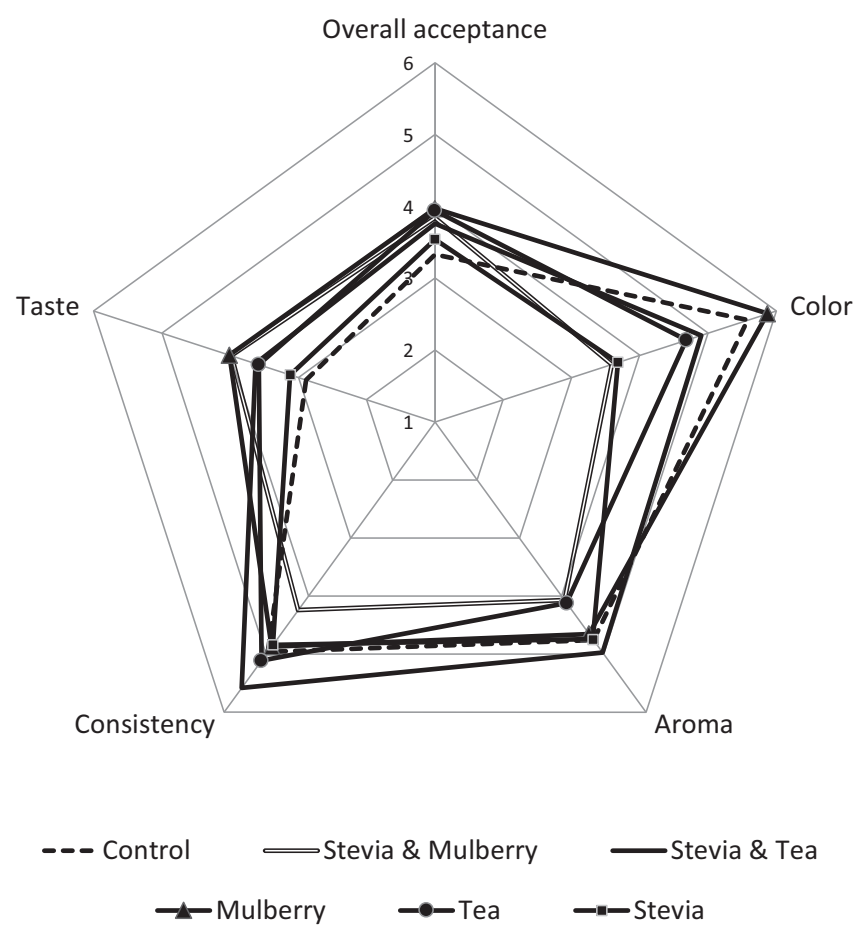

FIGURE 1. Sensory analysis of oat drinks with the addition of plant extracts and steviol glycosides.
TABLE 4. Pearson correlation coefficients calculated for a group of evaluated oat drinks.

\begin{tabular}{l|c|c|c|c|c}
\hline Assay & DPPH & ABTS & TPC & FRAP & ORAC \\
\hline DPPH & 1 & 0.993 & 0.934 & 0.952 & -0.613 \\
ABTS & 0.993 & 1 & 0.917 & 0.926 & -0.662 \\
TPC & 0.934 & 0.917 & 1 & 0.976 & -0.545 \\
FRAP & 0.952 & 0.926 & 0.976 & 1 & -0.614 \\
ORAC & -0.613 & -0.662 & -0.545 & -0.614 & 1 \\
\hline
\end{tabular}

says showed a weak negative correlation with antioxidant activity determined with the DPPH, ABTS and FRAP assays, as well as with total phenolics content. Roy et al. [2010] evaluated the structure and activity relationship in radical scavenging assays, and stated that the number of $\mathrm{OH}$ substitutions was poorly correlated with the ORAC value of tea components. In conclusion, it enabled presuming that substances exhibiting a lower antioxidant capacity may apply to a pro-oxidant effect via generating reactive oxygen species in an aqueous buffer of physiological pH. In turn, Payne et al. [2013] concluded that the variability between the methods is due to the chemistry behind the assays, as well as inference, reaction kinetics, and quantitation methods.

The results presented by Sun et al. [2006] showed the significant capability of oat components in preventing cholesterol oxidation during heating, proving their strong antioxidative potential. Antioxidants present in oats also stabilize oils and lipids against rancidity, ensuring a stable processed oat product [Peterson, 2001]. Antioxidant components such as simple phenolic compounds and avenanthramides in oats (Avena sativa) may have health-promoting effects on humans; however, their concentrations vary within oat genotypes [Chang et al., 2013]. Phenolic acid compositions in whole grains and their fractions were similar, with minor differences observed between the grain fractions of oats, yellow corn and barley and wheat [Ndolo \& Beta, 2014]. Emmons \& Peterson [2001] measured the antioxidant activity of extracts from oat (Avena sativa L.) groats and hulls and the concentrations of phenolic substances that may contribute to antioxidant activity. Their results showed a significantly higher antioxidant activity of oat groats than hulls, and differences in phenolic compound concentrations among cultivars and between fractions. In general, caffeic acid and the avenanthramides were predominant in groats, whereas higher concentrations of other phenolics were noted in hulls.

The analysis of selected radical scavenging capacities indicates that their values varied depending on the composition of the tested extract and the nature of the radical. Tea catechins can act as antioxidants in the systems by: scavenging, inhibition of enzymes, chelating of metal ions and regeneration of $\alpha$-tocopherol, stimulation of phase II detoxification enzymes or inhibition of transcription factors [Rice-Evans et al., 1996; Kmiecik et al., 2015]. The use of plant additives such as yellow tea and white mulberry extracts is, therefore, fully justified, as described and confirmed in the presented research work. The results of many phytonutrients studies indicate that 
the consumption of selected plant preparations, especially tea and mulberry, would be beneficial for consumers suffering from diabetes [Jankun et al., 2012; Banu et al., 2015]. What is also significant is that the results of the research showed that oat drinks fortified with plant extracts and steviol glycosides as a sucrose substitute were positively evaluated by consumers (Figure 1). Stevia preparations would benefit consumers who have to restrict carbohydrate intake within their diet and who enjoy the sweet taste with low calories and glucose level fluctuations. Considering the health effect of oat consumption, designing of new food products enriched with health-promoting phytonutrients is very important and preferred by consumers [Szakály et al., 2012].

One of the basic elements of food design is adequate composition, also in terms of the sensory characteristic of ingredients. The formulation of food products is based on the most favorable selection of proportions of different components. Consumer evaluations of oat drinks with bioactive additives are shown in Figure 1. The highest scores for overall desirability were given for oat drinks with the addition of yellow tea extract and mulberry extract, slightly lower results were recorded for the sample with steviol glycosides. The lowest score was noted for the control sample without additives. In terms of aroma, significantly higher scores were obtained by the sample with the addition of steviol glycosides and tea, followed by that without additives, and that with steviol glycosides. Consumers preferred the taste of oat drinks with mulberry and mulberry + steviol glycosides. The lowest acceptability was given to the control sample and the one with the addition of steviol glycosides. The most desirable color was declared for the oat drink with the addition of mulberry followed by the one without additives, while the least desirable was the sample with steviol glycosides. Consumer rating of drink consistency showed that the most favorable compared to the control was the sample containing steviol glycosides with tea extract. It should be noted that the results of the taste evaluation and overall desirability were similar, which indicates that in the choice of drinks consumers are primarily guided by taste.

\section{CONCLUSIONS}

In this study, the formula for an oat drink enriched with antioxidant phytochemicals was established. Results of the oat drinks proximate composition analysis showed moderate differences in the content of protein, lipids and fiber fractions, indicating the influence of the plant extracts added. Sensory evaluation of the designed oat drinks showed that the addition of steviol glycosides from Stevia rebaudiana was preferably received by consumers. Also, the mulberry and yellow tea extracts beneficially influenced the overall acceptance of phytonutrients fortified oat drinks. Among the oat drinks, the best antioxidant activity was recorded in the samples with the addition of the yellow tea extract. Results demonstrate a decrease in antioxidant activity, FRAP values and total phenols content after 5 days of storage.

Based on literature data, it can be concluded that the antioxidant properties of food are involved in the prevention and treatment of many diseases. Drinks made according to the designed formulation, using phyto-preparations, could have a beneficial health effect. Nevertheless, the fact that food is rich in antioxidants, it could be identified as intended for people with diabetes, cardiovascular diseases and other ailments caused by the disturbance of the red-ox homeostasis in the human body. The present research would help to expand scientific knowledge and indicate the possible applications in human trials evaluating the antioxidant influence of oat drinks fortified with steviol glycosides, mulberry and tea extracts. In summary, an oat drink fortified with plant extracts could be a potential alternative phenolic-rich functional food in grain-based food products. Moreover, plant extracts, with high functionality and nutritional value, can be employed in other food products as a suitable alternative to synthetic antioxidants.

\section{RESEARCH FUNDING}

Financial support was received from the UE Project nr PO IG 01.01.02.00-061/09 "Bioactive Food".

\section{CONFLICT OF INTERESTS}

Authors declare no conflict of interest.

\section{REFERENCES}

1. Alarcon E., Campos A.M., Edwards A.M., Lissi E., LopezAlcaron C., Antioxidant capacity of herbal infusions and tea extracts: a comparison of ORAC-fluorescein and ORAC-pyrogallol red methodologies. Food Chem., 2008, 107, 1114-1119.

2. AOAC. 1995. Official Methods of Analysis: Official Method for Protein. Method No. 920.87. Association of Official Analytical Chemists, Washington DC.

3. Bajerska J., Mildner-Szkudlarz S., Walkowiak J., Effects of rye bread enriched with green tea extract on weight maintenance and the characteristics of metabolic syndrome following weight loss: a pilot study. J. Med. Food, 2015, 18(6), 698-705.

4. Banu S., Jabir N.R., Manjunath N.C., Khan M.S., Ashraf G.M., Kamal M.A., Tabrez S., Reduction of post-prandial hyperglycemia by mulberry tea in type-2 diabetes patients. Saudi J. Biol. Sci., 2015, 22, 32-36.

5. Behall K.M., Scholfield D.J., Hallfrisch J., Comparison of hormone and glucose responses of overweight women to barley and oats. J. Am. Coll. Nutr., 2005, 24, 182-188.

6. Benzie F.F., Strain J.J., The Ferring Reducing Ability of Plasma (FRAP) as a measure of "antioxidant power": The FRAP Assay. Anal. Biochem., 1996, 239, 70-76.

7. Budryn G., Zyżelewicz D., Nebesny E., Oracz J., Krysiak W., Influence of addition of green tea and green coffee extracts on the properties of fine yeast pastry fried products. Food Res. Int., 2013, 50(1), 157-160.

8. Butt M.S., Tahir-Nadeem M., Kashif Iqbal Kham M., Shabir R., Butt M.S., Oat: unique among the cereals. Eur. J. Nutr., 2008, 47, 68-79.

9. Chang H-C., Huang C-N., Yeh D-M., Wang S-J., Peng C-H., Wang C-J., Oat prevents obesity and abdominal fat distribution, and improves liver function in humans. Plant Foods Hum. Nutr., 2013, 68, 18-23. 
10. De S., Mondal S., Banerjee S., Stevioside Technology, Applications and Health. 2013, John Wiley and Sons, West Sussex, UK, $1^{\text {st }}$ Edition, pp. 27-35.

11. Duodu K.G., Taylor J.R.N., Belton P.S., Hamaker B.R., Factors affecting sorghum protein digestibility. J. Cereal Sci., 2003, 38, 117-131.

12. Dziedzic K., Górecka D., Kucharska M., Przybylska B., Influence of technological process during buckwheat groats production on dietary fibre content and sorption of bile acids. Food Res. Int., 2012, 47, 279-283.

13. Emmons C.L., Peterson D.M., Antioxidant activity and phenolic content of oat as affected by cultivar and location. Crop Sci., 2001, 41, 1678-1681.

14. Ercisli S., Orhan E., Chemical composition of white (Morus alba), red (Morus rubra) and black (Morus nigra) mulberry fruits. Food Chem., 2007, 103, 1380-1384.

15. Gramza-Michałowska A., Kobus-Cisowska J., Kmiecik D., Korczak J., Helak B., Dziedzic K., Górecka D., Antioxidative potential, nutritional value and sensory profiles of confectionery fortified with green and yellow tea leaves (Camellia sinensis). Food Chem., 2016, 211, 448-454.

16. Gramza-Michałowska A., Caffeine in tea Camellia sinensis content, absorption, benefits and risks of consumption. J. Nutr. Health Aging, 2014, 18, 143-149.

17. Gramza-Michałowska A., Sidor A., Reguła J., Kulczyński B., PCL assay application in superoxide anion-radical scavenging capacity of tea Camellia sinensis extracts. Acta Sci. Pol., Technol. Aliment., 2015, 14(4), 331-341.

18. Gregersen S., Jeppesen P.B., Holst J.J., Hermansen K., Antihyperglycemic effects of stevioside in type 2 diabetic subjects. Metab. Clin. Experim., 2004, 54, 73-76.

19. Hüttner E.K., Arendt E.K., Recent advances in gluten free baking and the current status of oats. Trends Food Sci. Tech., 2010, 21, 303-312.

20. ISO 11136:2014. Sensory analysis - Methodology - General guidance for conducting hedonic tests with consumers in a controlled area.

21. Jakobek L., Interactions of polyphenols with carbohydrates, lipids and proteins. Food Chem., 2015, 175, 556-567.

22. Jankun J., Al-Senaidy A., Skrzypczak-Jankun E., Can drinking black tea fight diabetes: literature review and theoretical indication. Centr. Eur. J. Immunol., 2012, 37, 167-172.

23. Kimura T., Nakagawa K., Kubota H., Goto Y., Yamagishi K., Oita S., Oikawa S., Mayazawa T., Food-grade mulberry powder enriched with 1-deoxynojirimycin suppresses the elevation of postprandial blood glucose in humans. J. Agric. Food Chem., 2007, 55, 5869-5874.

24. Kmiecik D., Korczak J., Rudzińska M., Gramza-Michałowska A., Hęś M., Kobus-Cisowska J., Stabilization of phytosterols by natural and synthetic antioxidants in high temperature conditions. Food Chem., 2015, 173, 966-971.

25. Kujawska M., Ewertowska M., Ignatowicz E., Adamska T., Szaefer H., Gramza-Michałowska A., Korczak J., Jodynis-Liebert J., Evaluation of safety and antioxidant activity of yellow tea (Camellia sinensis) extract for application in food. J. Med. Food, 2016, 19(3), 1-7.

26. Le Bourvellec C., Watrelot A.A., Ginies C., Imberty A., Renard C.M.G.C., Impact of processing on the noncovalent interactions between procyanidin and apple cell wall. J. Agric. Food Chem., 2012, 60(37), 9484-9494.

27. Nam S., Jang H.W., Shibamoto T., Antioxidant activities of extracts from teas prepared from medicinal plants, Morus alba L., Camellia sinensis L., and Cudrania tricuspidata, and their volataile components. J. Agric. Food Chem., 2012, 60(36), 9097-90105.

28. Ndolo V.U., Beta T., Comparative studies on composition and distribution of phenolic acids in cereal grain botanical fractions. Cereal Chem., 2014, 91, 522-530.

29. Niidome T., Takahashi K., Goto Y., Goh S., Tanaka N., Kamei K., Ichida M., Hara S., Akaike A., Kihara T., Sugimoto H., Mulberry leaf extract prevents amyloid beta-peptide fibryl formation and neurotoxicity. Neuroreport, 2007, 18, 813-816.

30. Ozdal T., Capanoglu E., Altay F., A review on protein-phenolic interactions and associated changes. Food Res. Int., 2013, 51, 954-970.

31. Önning G., Wallmark K., Persson M., Akesson B., Elmstahl S., Oste R., Consumption of oat milk for 5 weeks lowers serum cholesterol and LDL cholesterol in free-living men with moderate hypercholesterolemia. Ann. Nutr. Metab., 1999, 43, 301-309.

32. Payne A., Mazzer A., Clarkson G.J.J., Taylor G., Antioxidant assays - consistent findings from FRAP and ORAC reveal a negative impact of organic cultivation on antioxidant potential in spinach but not watercress or rocket leaves. Food Sci. Nutr., 2013, 1(6), 439-444.

33. Pang G., Xie J., Chen Q., Hu Z., How functional foods play critical roles in human health. Food Sci. Hum. Well., 2012, 1, 26-60.

34. Peterson D.M., Oat antioxidants. J. Cereal Sci., 2001, 33, 115-129.

35. Polish Standard PN-EN ISO 3947:2001P. Starches, native or modified - determination of total fat content.

36. Polish Standard PN-A-79011-8:1998. Dry food mixes - test methods - determination of total ash content and ash insoluble in 10 percent $(\mathrm{m} / \mathrm{m})$ hydrochloric acid.

37. Prigent S.V.E., Voragen A.G.J., van Koningsveld G.A., Baron A., Renard C.M.G.J., Gruppen H., Interactions between globular proteins and procyanidins of different degrees of polymerization. J. Dairy Sci., 2009, 92, 5843-5853.

38. Re R., Pellegrini N., Proteggente A., Pannala A., Yang M., RiceEvans C., Antioxidant activity applying an improved ABTS radical cation decolorization assay. Free Rad. Biol. Med., 1999, 26, 1231-1237.

39. Rice-Evans C.A., Miller N.J., Paganga G., Structure - antioxidant activity relationships of flavonoids and phenolic acids. Free Rad. Biol. Med., 1996, 20, 933-956.

40. Riou V., Vernhet A., Doco T., Moutounet M., Aggregation of grape seed tannins in model wine - effect of wine polysaccharides. Food Hydrocoll., 2002, 16(1), 17-23.

41. Roy M.K., Koide M., Rao T.P., Okubo T., Ogasawara Y., Juneja L.R., ORAC and DPPH assay comparison to assess antioxidant capacity of tea infusions: relationship between total polyphenol and individual catechin content. Int. J. Food Sci. Nutr., 2010, 61(2), 109-124.

42. Sajilata M.G., Bajaj P.R., Singhal R.S., Tea polyphenols as nutraceuticals. Compr. Rev. Food Sci., 2008, 7, 229-254.

43. Sanchez-Moreno C., Larrauri J.A., Saura-Calixto F., A procedure to measure the antiradical efficiency of polyphenols. J. Sci. Food Agric., 1998, 76, 270-276. 
44. Shahidi F., Naczk M., Methods of analysis and quantification of phenolic compounds. 1995, in: Food Phenolic: Sources, Chemistry, Effects and Applications. Technomic Publishing Company, Lancaster/Pensylvania, USA, pp. 287-293.

45. Sun T., Xu Z., Godber J.S., Prinyawiwatkul W., Capabilities of oat extracts in inhibiting cholesterol and long chain fatty acid oxidation during heating. Cereal Chem., 2006, 83, 451-454.

46. Szakály Z., Szente V., Kövér, G., Polereczki Z., Szigeti O., The influence of lifestyle on health behavior and preference for functional foods. Appetite, 2012, 58, 406-413.

47. Tadhani M.B., Patel V.H., Subhash R., In vitro antioxidant activities of Stevia rebaudiana leaves and callus. J. Food Comp. Anal., 2007, 20, 323-329.

48. Thabti I., Elfalleh W., Hannachi H., Ferchichi A., Da Graca Campos M., Identification and quantification of phenolic acids and flavonol glycosides in Tunisian Morus species by HPLC-DAD and HPLC-MS. J. Funct. Foods, 2012, 4, 367-374.

49. Vichasilp C., Nakagawa K., Sookwong P., Higuchi O., Luemunkong S., Miyazawa T., Development of high 1-deoxynojirimycin (DNJ) content mulberry tea and use of response surface methodology to optimize tea-making conditions for highest DNJ extraction. LWT - Food Sci. Technol., 2012, 45, 226-232.

50. Yen G.C., Chen H.Y., Antioxidant activity of various tea extracts in relation to their antimutagenicity. J. Agric. Food Chem., 1995, 43, 27-32.

51. Yu L., Perret J., Davy B., Wilson J., Melby C.L., Antioxidant properties of cereal products. J. Food Sci., 2002, 67, 2600-2603.

Submitted: 12 April 2016. Revised: 12 and 23 October 2016. Accepted: 7 December 2016. Published on-line: 17 May 2017. 
